\title{
PERENCANAAN STRATEGIS SISTEM INFORMASI DI PT TELEKOMUNIKASI INDONESIA, TbK WITEL SEMARANG MENGGUNAKAN WARD AND PEPPARD
}

\author{
Adi Wiyono', Agustinus Fritz Wijaya ${ }^{2}$ \\ Program Sarjana Sistem Informasi \\ Universitas Kristen Satya Wacana \\ email :1,2682016077@student.uksw.edu, agustinus.wijaya@uksw.edu, \\ J1. Diponegoro 52-60, Salatiga 50711, Indonesia
}

\begin{abstract}
PT Telekomunikasi Indonesia is a State-Owned Enterprise (BUMN) engaged in the field of communication information technology services and telecommunications networks in Indonesia. In running its business, PT Telekomunikasi Indonesia has used technology to run its business. PT Telekomunikasi Indonesia has several divisions that are ready to work in accordance with existing procedures. It is expected that the existence of Human Resources (HR) that is owned now can provide added value to the company PT. Telekomunikasi Indonesia Witel Semarang. The current Human Resources, in the use of technology at PT Telekomunikasi Indonesia Witel Semarang is still not optimal. Given this problem, this research was made using the Ward and Peppard method, with several analytical techniques using PEST and Value Chain techniques to analyze the internal and external environment of the business, SWOT to analyze the internal and external environments of SI and IT, and McFarlan Strategic Grid for mapping application portfolio. This research is expected to improve performance or service for customers in accordance with the company's business goals.
\end{abstract}

Kata kunci: Perencanaan Strategis Sistem Informasi, SWOT, Ward and Peppard, Value Chain

\begin{abstract}
Abstrak
PT Telekomunikasi Indonesia adalah Badan Usaha Milik Negara (BUMN) yang bergerak di bidang layanan teknologi informasi komunikasi dan jaringan telekomunikasi di Indonesia. Dalam menjalankan bisnisnya, PT Telekomunikasi Indonesia telah menggunakan teknologi untuk menjalankan bisnisnya. PT Telekomunikasi Indonesia memiliki beberapa divisi yang siap bekerja sesuai dengan prosedur yang ada. Diharapkan dengan adanya Sumber Daya Manusia ( SDM ) yang dimiliki sekarang dapat memberi nilai tambah bagi perusahaan PT. Telekomunikasi Indonesia Witel Semarang. Sumber Daya Manusia yang di miliki saat ini, dalam penggunakaan teknologi di PT Telekomunikasi Indonesia Witel Semarang masih belum optimal. Dengan adanya masalah ini, penelitian ini dibuat dengan menggunakan metode Ward and Peppard, dengan beberapa teknik analisis menngunakan teknik PEST dan Value Chain untuk menganalisis lingkungan internal dan eksternal bisnis, SWOT untuk menganalisis lingkungan internal dan eksternal SI dan TI, dan McFarlan Strategic Grid untuk pemetaan portofolio aplikasi. Penelitian ini diharapkan dapat meningkatkan kinerja atau layanan bagi pelanggan sesuai dengan tujuan bisnis perusahaan.
\end{abstract}

Kata kunci: Perencanaan Strategis Sistem Informasi, SWOT, Ward and Peppard, Value Chain 


\section{PENDAHULUAN}

Dewasa ini dalam upaya memenangkan persaingan dalam dunia bisnis, penerapan teknologi informasi dan komunikasi sangat diperlukan sebagai alat bantu agar organisasi tersebut dapat lebih maju dan berkembang. Pembangunan teknologi informasi dan sistem informasi pada suatu perusahaan dilakukan secara bertahap, hal tersebut disesuaikan berdasarkan kekuatan dari sumber daya yang dimiliki oleh organisasi tersebut. Ada tiga sasaran utama dari upaya penerapan SI/TI dalam suatu organisasi. Pertama, memperbaiki efisiensi kerja dengan melakukan otomasi berbagai proses yang mengelola informasi. Kedua, meningkatkan keefektifan manajemen dengan memuaskan kebutuhan informasi guna pengambilan keputusan. Ketiga, memperbaiki daya saing atau meningkatkan keunggulan kompetitif organisasi dengan merubah gaya dan cara berbisnis (Ward and Peppard, 2002). Di dalam penerapannya tersebut, rencana strategis dari suatu teknologi informasi senantiasa disesuaikan dengan rencana dari perusahaan atau organisasi yang bersangkutan, supaya penerapan dari teknologi informasi tersebut dapat menghasilkan nilai yang baik bagi perusahaan atau organisasi tersebut. Salah satu organisasi yang sudah menerapkan SI/TI adalah PT. Telekomunikasi Indonesia (Persero) Tbk (Telkom).

PT Telkom adalah Badan Usaha Milik Negara (BUMN) yang bergerak di bidang jasa layanan teknologi informasi dan komunikasi dan jaringan telekomunikasi di Indonesia. Pada tahun 1961, Pemerintah Indonesia mendirikan Perusahaan Negara Pos dan Telekomunikasi (PN Postel). Namun, seiring perkembangan pesat layanan telepon dan telex, Pemerintah Indonesia mengeluarkan PP No. 30 tanggal 6 Juli 1965 untuk memisahkan industri pos dan telekomunikasi. Dengan pemisahan ini, setiap perusahaan dapat fokus untuk mengelola portofolio bisnisnya masing-masing. Terbentuknya PN Telekomunikasi ini menjadi cikal-bakal Telkom saat ini. Saat ini TelkomGroup mengelola 6 produk portofolio yang melayani empat segmen konsumen, yaitu korporat, perumahan, perorangan dan segmen konsumen lainnya. Produk-produk tersebut adalah Mobile, Fixed, Wholesale \& International, Network, Enterprise Digital, dan Consumer Digital. Dalam meningkatkan layanan serta menjalankan bisnis sesuai dengan tujuan perusahaan PT.Telkom Indonesia memiliki Divisi Long Distance, Carrier dan Interconnection Service, Divisi Multimedia, Divisi Fixed Wireless Network, Divisi Enterprise Service, Divisi Regional, Carrier Development Support Centre, Management Consulting Centre, Contruction Centre, Community Development Centre (CDC), Divisi Infratel (Infrastruktur Telekomunikasi), Divisi Consumere Care. Divisi yang dimiliki PT. Telekomunikasi Indonesia sekarang ini diharapkan oleh PT. Telekomunikasi Indonesia, Tbk Witel Semarang dapat meningkatkan produktivitas pada perusahaan dengan mengedepankan fasilitas TI yang ada sekarang. Dalam pengguaan TI saat ini PT. Telekomunikasi Indonesia, Tbk Witel Semarang telah menggunakan fasilitas TI pada tiap divisi yang dimilikinya, hanya saja penggunaan IT pada bagian beberapa divisi masih belum maksimal untuk menunjang kinerja proses bisnisnya. Berdasarkan hal tersebut diperlukannya perencanaan strategis Sistem Informasi. Dengan perencanaan strategis organisasi dapat berkembang baik dari aspek pemberdayaan sumber daya manusianya, kinerja bisnis akan lebih efisien sehingga mampu meningkatkan kompetensi manajemen dan kepemimpinan.

Dengan adanya permasalahan tersebut, penggunaan metode Ward And Peppard dengan melihat kebutuhan kondisi bisnis PT. Telekomunikasi Indonesia, Tbk Witel Semarang saat ini adalah penggunaan metode yang tepat. karena metode ini dimulai dari proses analisis kondisi bisnis dan investasi SI/TI yang sudah berjalan yang di nilai kurang efektif, lalu kemudian menganalisa kondisis bisnis eksternal sehingga dapat membandingkan pemanfaatan SI/TI apakah sudah maksimal dengan kecenderungan kondisi SI/TI yang digunakan di luar. Terkadang kurang bermanfaatnya SI/TI disebabkan organisasi lebih fokus pada teknologi tanpa melihat kebutuhan bisnisnya. Adapun beberapa teknik analisis metode Ward and Peppard dengan menggunakan 
teknik analisis PEST dan Value Chain untuk menganalisis lingkungan internal dan eksternal bisnis, SWOT untuk menganalisis lingkungan internal dan eksternal SI maupun TI, dan McFarlan Strategic Gird yang digunakan untuk pemetaan portofolio aplikasi. Dengan demikian diharapkan hasil dari penelitian dapat digunakan untuk meningkatkan proses bisnis yang efektif dan sesuai dengan tujuan perusahaan PT. Telekomunikasi Indonesia, Tbk.

\subsection{TINJAUAN PUSTAKA}

\subsubsection{Strategi Sistem Informasi}

Mengembangkan sebuah strategi SI/TI berarti berpikir secara strategis dan merencanakan manajemen yang efektif untuk jangka waktu yang lama, dan dampak yang optimal dari informasi, baik dalam bentuk sistem informasi dan teknologi informasi yang menggabungkan manual dan sistem komputer, teknologi komputer dan telekomunikasi. Termasuk juga aspek organisasional dari manajemen SI/TI. Strategi SI dapat membantu mencapai tujuan bisnis organisasi. Pemahaman terhadap kebutuhan informasi dapat mendukung tujuan tersebut, kemudian implementasi dari sistem komputer untuk menyediakan informasi. Hal ini merupakan rencana untuk pengembangan sistem menuju visi dari peran SI di organisasi.

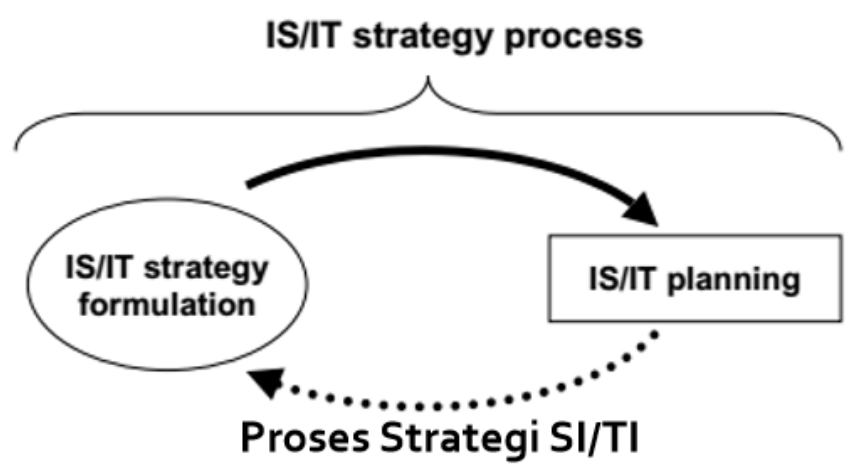

Gambar 1. Proses Strategi SI/TI

Proses Strategi SI/TI mengacu pada perencanaan. Dimana Strategi SI/TI mendorong perencanaan SI/TI, dan dalam membangun perencanaan SI/TI akan timbul aspek-aspek yang menyebabkan tinjauan ulang terhadap Strategi SI/TI

\subsubsection{Perencanaan Strategi Sistem Informasi}

Perencanaan Strategi SI/TI merupakan proses identifikasi portfolio aplikasi sistem informasi berbasis komputer yang akan mendukung organisasi dalam pelaksanaan rencana bisnis untuk merealisasikan tujuan bisnisnya. Penulis melakukan penelitian ini. Faktor terpenting dalam proses perencaan strategi SI/TI adalah penggunaan metodologi untuk meminimalkan resiko kegagalan, memastikan keterlibatan semua pihak yang bekepentingan, serta lebih menekankan sasaran yang diinginkan. Adapun masukan dalam penyusunan perencanaan strategis ini yaitu lingkungan bisnis internal, lingkungan bisnis eksternal, lingkungan SI/TI internal, dan lingkungan SI/TI eksternal. Output dari perencanaan strategis nantinya akan menghasilkan strategi bisnis sistem informasi, strategi teknologi informasi, dan strategi manajemen. Beberapa metode yang akan di gunakan dalam penelitian ini yaitu analisis Value Chain untuk menganalisis lingkungan internal dan 
eksternal bisnis, SWOT untuk menganalisis lingkungan internal dan eksternal SI maupun TI, dan McFarlan Strategic Gird yang digunakan untuk pemetaan portofolio aplikasi.

Penelitian perencanaan strategi SI/TI yang dilakukan oleh Anharudin (2015) dengan judul "Perencanaan Strategis Sistem Informasi untuk Meningkatkan Pelayanan Menggunakan Metode Ward And Peppard" ( Studi Kasus : PT. Pos Indonesia Cilegon-Banten ). Penelitian ini membahas rencana bisnis PT Pos Indonesia dengan hasil evaluasi terhadap karakteristik dan proses bisnis saat ini yang menunjukkan bahwa, diperlukan sistem informasi (SI) yang baik untuk meningkatkan kinerja dan daya saing.

Penelitian lainnya yang dilakukan oleh Awan Setiawan dan Benie Ilman (2012) dengan judul "Perencanaan Strategik Sistem Informasi pada Perusahaan Penerbitan dengan Metode Ward and Preppard: Studi Kasus pada Penerbit Rekayasa Sains Bandung”. Penelitian ini menggunakan Metode Ward and Peppard untuk menyusun sebuah perencanaan strategic sistem infomrasi pada suatu industri. Dengan adanya metode ini dapat dijadinya dasar dalam penyusunan perencanaan strategis, dengan hasil kajian yang menunjukan model perencanaan strategi sistem informasi industry penerbitan yang selaras dengan strategi bisnisnya.

Penelitian lainnya juga dilakukan oleh Purnomo dan Febriliyan (2017) dengan judul "Perencanaan Strategis Sistem Informasi / Teknologi Informasi Di Balai Riset Dan Standardisasi Industri Surabaya". Penelitian ini membahas kegitan operasional bisnisnya dengan menggunakan aset-aset IT yang di miliki pada Baristand Industri Surabaya dengan adanya tuntutan-tuntutan baru yang menyebabkan paradigma pengelolaan TI dan kegiatan operasionalnya menjadi keberhasilan dalam menyusun strategi. Cara pengelolaan TI yang berjalan dirasa sudah tidak lagi maksimal untuk mendukung strategi, solusi yang digunakan pada penelitian ini adalah dengan penyususnan perencanaan strategis SI/TI dengan metode Ward and Peppard.

Dari penelitian-penelitian tersebut dapat diharapkan membantu memaksimalkan penggunaan aset-aset TI yang dimiliki PT. Telekomunikasi Indonesia, Tbk Witel Semarang untuk meningkatkan pelayanan yang sesuai dengan strategi bisnisnya dan akan memberikan nilai tambah dalam daya saing bisnis. 


\section{METODOLOGI PENELITAN}

\subsection{Metodologi Ward and Peppard}

Dalam penelitian ini digunakan metode Ward and Peppard dengan menggunakan beberapa teknik analisis Value Chain untuk menganalisis lingkungan internal dan eksternal bisnis, SWOT untuk menganalisis lingkungan internal dan eksternal SI maupun TI, dan McFarlan Strategic Gird yang digunakan untuk pemetaan portofolio aplikasi. Metode Ward And Peppard digunakan penulis karena metode ini dimulai dari proses anilisis kondisi bisnis dan investasi SI/TI yang sudah berjalan yang di nilai kurang efektif, lalu kemudian menganalisa kondisis bisnis eksternal sehingga dapat membandingkan pemanfaatan SI/TI apakah sudah maksimal dengan kecenderungan kondisi SI/TI yang digunakan di luar.

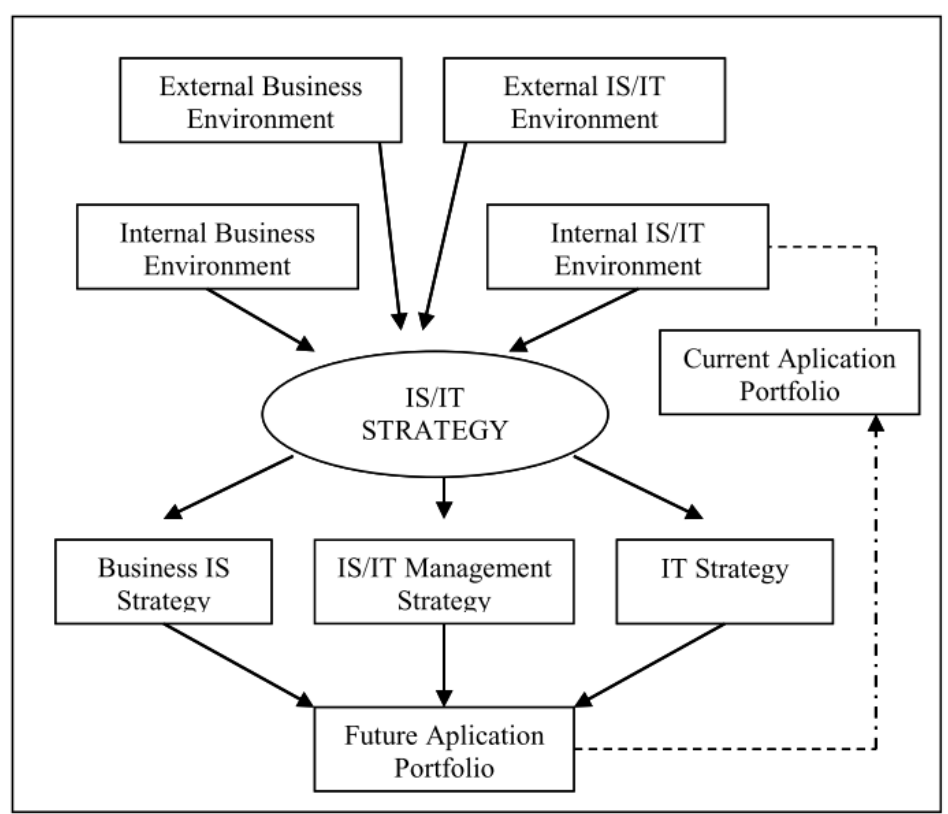

Gambar 2. Model Perencanaan Strategi SI/TI (Ward and Peppard 2002).

Tahapan-tahapan masukan model perencanaan strategis SI/TI.

1. Analisis Lingkungan Bisnis Internal SI/TI, yang mencakup tentang proses bisnis saat ini di PT Telekomunikasi Indonesia, Tbk Witel Semarang untuk mencapai tujuan organisasi sehingga dapat menjadi nilai tambah untuk organisasi.

2. Analisis Lingkungan Bisnis Eksternal SI/TI, yang mencakup tentang politik, ekonomi, sosial, dan teknologi (PEST).

3. Analisis Lingkungan Internal SI/TI, yang mencakup tentang kondisi SI/TI di PT Telekomunikasi Indonesia, Tbk Witel Semarang dengan melihat pemanfaatan terhadap kondisi bisnis saat ini, bagaimana kontribusi SI/TI terhadap bisnis, SDM dan Insfrastruktur SI/TI.

4. Analisis Lingkungan Eksternal SI/TI, yang mencakup tren teknologi dan pemanfaatannya oleh pelanggan dan kompetitor.

Tahapan-tahapan keluaran model perencanaan strategis SI/TI.

1. Strategi Bisnis SI, mencakup pemanfaatan SI/TI untuk mencapai sasaran bisnis organisasi di PT Telekomunikasi Indonesia, Tbk Witel Semarang.

2. Strategis TI, mencakup strategi pengelolaan sumber daya manusia di PT Telekom Indonesia, Tbk dengan pemanfaatan teknologi yang ada. 
3. Strategi Manajemen SI/TI, mencakup penerapan kebijakan SI/TI yang dibutuhkan di PT Telekomunikasi Indonesia, Tbk Witel Semarang.

\subsection{PEST Analysis}

Analisis atau alat perencanaan strategis yang digunakan untuk mengevaluasi dampak dari faktor-faktor Politik, Ekonomi, Sosial dan Teknologi terhadap suatu proyek.

\subsection{Value Chain Analysis}

Analisis ini bertujuan untuk mengidentifikasi dan mengelompokkan aktivitas-aktivitas yang terjadi di lingkungan PT. Telekomunikasi Indonesia, Tbk Witel Semarang baik lingkungan internal maupun lingkungan eksternal ke dalam beberapa bagian untuk menentukan solusi SI/TI guna menghasilkan keunggulan bagi perusahaan.

\subsection{SWOT Analysis}

SWOT digunakan untuk identifikasi faktor internal bisnis yang terdiri dari kekuatan (strength) dan kelemahan (weakness) dan factor eksternal bisnis terdiri dari peluang (opportunity) dan ancaman (threat) dari suatu organisasi. Hasil dari analisis SWOT nantinya dapat menjadi pembanding untuk memaksimalkan kekuatan dan peluang serta meminimalkan kelemahan dan ancaman.

\subsection{Mc Farlan Strategic Grid Analysis}

McFarlan strategic grid digunakan untuk memetakan aplikasi SI berdasarkan kontribusinya terhadap organisasi. Pemetaan dilakukan pada empat kuadran (strategic, high potential, key operation, and support) Dari hasil pemetaan tersebut diperoleh gambaran konstribusi sebuah aplikasi SI terhadap organisasi dan pengembangan di masa mendatang.

\section{HASIL DAN PEMBAHASAN}

\subsection{Mc Farlan Strategic Grid Analysis}

a. Politik

- Membuka kompetisi pasar bebas yang di atur undang undang guna memberikan manfaat bagi kesejahteraan masyarakat.

b. Ekonomi

- Penyediaan jaringan jaringan dengan pengadaan perangkat yang mendukung perluasan jaringan telekomunikasi dan perluasan jaringan internet.

c. Sosial

- Memberikan brand awareness kepada konsumen melalui media sosial seperti WhatsApp dan Facebook.

- Melakukan kegiatan sosialisasi dan event layanan produk-produk PT. Telekomunikasi Indonesia, Tbk Witel Semarang

d. Teknologi

- Maintenance secara berkala tiap 1 bulan.

- Pembaharuan, pencetusan inovasi, dan pembuatan aplikasi baru untuk mendukung proses bisnis di PT. Telekomunikasi Indonesia, Tbk Witel Semarang saat ini. 


\subsection{Value Chain Analysis}

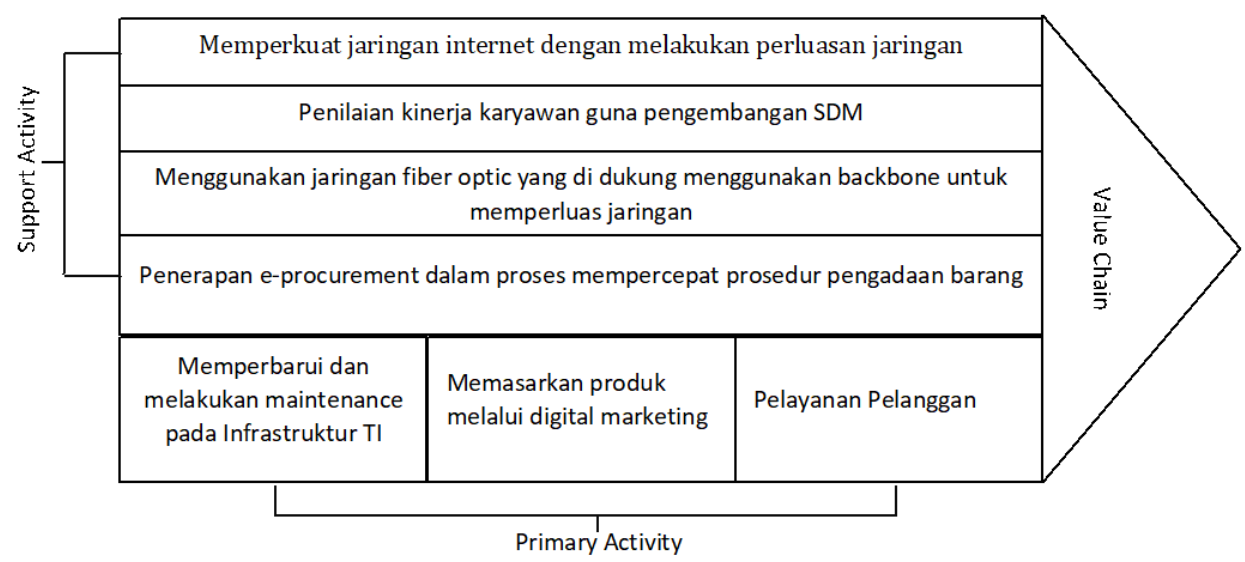

Gambar 3. Diagram Value Chain ( Ward and Peppard, 2002 )

Aktivitas utama dan aktivitas pendukung pada PT. Telekomunikasi Indonesia, Tbk Witel Semarang digambarkan melalui diagram value chain meliputi :

1. Primary Activity :

a. Memperbarui dan melakukan maintenance pada Insfrastruktur TI.

b. Memasarkan produk melalui digital marketing.

c. Pelayanan pelanggan

2. Support Activity :

a. Memperkuat jaringan internet dengan melakukan perluasan jaringan.

b. Penilaian kinerja karyawan guna pengembangan SDM.

c. Menggunakan jaringan fiber optic yang didukung menggunakan backbone untuk memperluas jaringan.

d. Penerapan e-procurement dalam proses mempercepat prosedur pengadaan barang.

\subsection{Analysis SWOT}

Analisis terakhir yang digunakan untuk menarik kesimpulan menyeluruh dari semua analisi yang ada selanjutnya digunakan yakni analisis SWOT. Yang nantinya dengan analisis SWOT dapat menyusun strategi untuk perusahaan sebagaimana digambarkan berikut ini. 


\begin{tabular}{|c|c|c|}
\hline \multirow[b]{2}{*}{ EKSTERNAL } & STRENGHT (S) & WEAKNESS (W) \\
\hline & 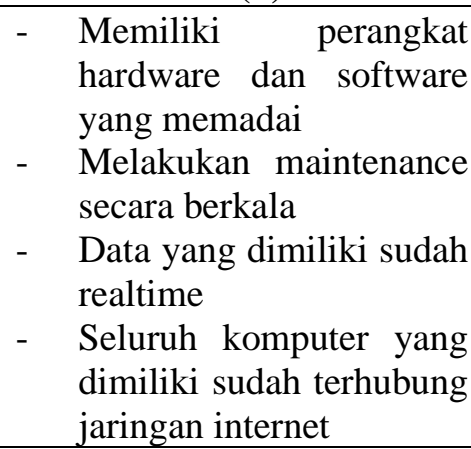 & $\begin{array}{ll}\text { - } & \text { Kualitas SDM yang } \\
\text { dimiliki masih kurang } \\
\text { - } & \text { Kekurangan staff bagian } \\
\text { SI/TI yang dapat } \\
\text { menunjang tujuan proses } \\
\text { bisnis perusahaan } \\
\text { - } \begin{array}{l}\text { Proses kerja tiap divisi } \\
\text { belum optimal }\end{array}\end{array}$ \\
\hline OPORTUNITY(O) & S-O & W-O \\
\hline 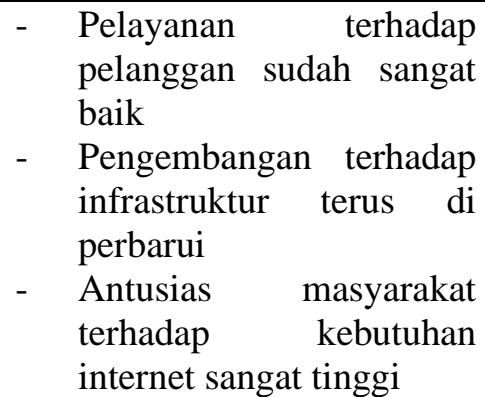 & 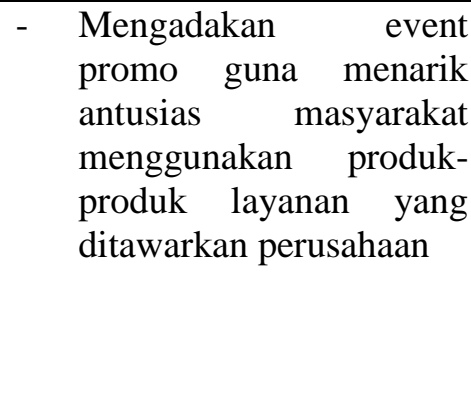 & $\begin{array}{l}\text { Penambahan staff SI/TI } \\
\text { yang dapat menunjang } \\
\text { kebutuhan tujuan proses } \\
\text { bisnis perusahaan }\end{array}$ \\
\hline THEART (T) & S-T & W-T \\
\hline $\begin{array}{l}\text { Pencurian dan perusakan } \\
\text { terhadap infrastruktur } \\
\text { yang dimiliki } \\
\text { Persaingan harga layanan } \\
\text { produk yang ditawarkan } \\
\text { Kebocoran data-data } \\
\text { pelanggan }\end{array}$ & $\begin{array}{l}\text { - Melakukan maintenance } \\
\text { secara berkala terhadap } \\
\text { bagian keamanan SI/TI }\end{array}$ & $\begin{array}{l}\text { Kekuarangan } \\
\text { bagian Staff } \\
\text { memberikan dapat dampak } \\
\text { resiko kebocoran } \\
\text { pencurian data dan tidak } \\
\text { terurusnya sistem yang } \\
\text { ada }\end{array}$ \\
\hline
\end{tabular}

Tabel 1. Matriks SWOT

\subsection{Aplikasi Portofolio}

Berikut penyusunan portofolio aplikasi untuk beberapa tahun mendatang, berdasarkan analisa yang sudah dilakukan pada perusahaan seputar lingkungan bisnis, kondisi SI/TI internal dan eksternal. Dalam penyusunan ini yang digunakan ialah metode Mc Farlan Grid dalam pemetakan aplikasi yang terdiri empat kuadran yakni Strategic, High Potential, Key Operation, dan Support.

\begin{tabular}{|c|c|}
\hline Strategic & High Potential \\
\hline $\begin{array}{ll}- & \text { Manajemen SDM } \\
- & \text { Sistem Informasi Web Telkom }\end{array}$ & $\begin{array}{ll}\text { - } & \text { Aplikasi Web penilain pelayanan dari } \\
\text { pelanggan } \\
\text { - Web pencatatan data pelanggan bagian } \\
\text { Consumere Care }\end{array}$ \\
\hline $\begin{array}{ll}\text { - } & \text { Aplikasi MyIndihome } \\
\text { - } & \text { Aplikasi MyTelkomsel } \\
\text { - } & \text { Link Aja }\end{array}$ & $\begin{array}{ll}\text { - } & \text { Proses pengadaan barang } \\
\text { - } & \text { Analisis kinerja karyawan }\end{array}$ \\
\hline
\end{tabular}




\begin{tabular}{|c|c|}
\hline$-\quad$ Usee Tv & \\
$-\quad$ Regristasi Pelanggan & Support \\
\hline \multicolumn{1}{|c|}{ Key Operational } & Supratikasi \\
\hline
\end{tabular}

Tabel 2. Portofolio Aplikasi

\subsection{Rekomendasi SI/TI}

Selanjutnya rekomendasi SI/TI pada perusahaan PT. Telekomunikasi Indonesia, Tbk Witel Semarang, berisikan rekomendasi untuk peningkatan kinerja pada perusahaan dalam jangka waktunya. Pembuatan rekomendasi ini berdasarkan hasil dari analisa-analisa yang ada, guna menunjang pencapaian tujuan perusahaan dengan kinerja yang efektif dan efisien.

\begin{tabular}{|c|c|c|c|c|c|c|c|}
\hline \multicolumn{3}{|c|}{ Rekomendasi } & \multicolumn{5}{|c|}{ Tahun } \\
\hline No & $\begin{array}{l}\text { Nama Sistem } \\
\text { Informasi }\end{array}$ & Penjelasan & 2021 & 2022 & 2023 & 2024 & 2025 \\
\hline 1. & $\begin{array}{l}\text { Aplikasi } \\
\text { Penilaian } \\
\text { terhadap } \\
\text { pelayanan dari } \\
\text { pelanggan }\end{array}$ & $\begin{array}{l}\text { Aplikasi ini nantinya digunakan } \\
\text { untuk pengukuran kerja } \\
\text { karyawan terhadap pelayanan } \\
\text { yang diberikan terhadap } \\
\text { konsumen }\end{array}$ & & & & $\checkmark$ & \\
\hline 2. & $\begin{array}{l}\text { Aplikasi } \\
\text { pencatatan dan } \\
\text { pengiriman } \\
\text { data pelanggan } \\
\text { untuk bagian } \\
\text { Consumere } \\
\text { Care }\end{array}$ & $\begin{array}{l}\text { Pada saat ini Telkom witel } \\
\text { Semarang dalam melakukan } \\
\text { pecatatan data pelanggan pada } \\
\text { bagian Consumer Care masih } \\
\text { menggunakan excel dan } \\
\text { dikirimkan kepada bagian agen } \\
\text { promosi melalui telegram untuk } \\
\text { nantinya data akan di acak } \\
\text { secara manual. Aplikasi ini } \\
\text { dibuat nantinya dapat } \\
\text { memudahkan dalam } \\
\text { pengambilan data pelanggan } \\
\text { yang akan terhubung pada } \\
\text { database konsumen Telkom } \\
\text { witel Semarang dan nantinya } \\
\text { akan ada fitur pengacakan data } \\
\text { secara otomatis }\end{array}$ & & & $\checkmark$ & & \\
\hline 3. & $\begin{array}{l}\text { Pengadaan } \\
\text { aplikasi WA } \\
\text { Bomber }\end{array}$ & $\begin{array}{l}\text { Telkom witel Semarang } \\
\text { memerlukan aplikasi WA } \\
\text { Bomber Full Licensi untuk } \\
\text { melakukan promosi produk } \\
\text { baru kepada konsumennya } \\
\text { secara cepat dan otomatis } \\
\text { melalui WhatsApp. }\end{array}$ & & $\checkmark$ & & & \\
\hline 4. & $\begin{array}{l}\text { Pengembangan } \\
\text { data server } \\
\text { pelanggan }\end{array}$ & $\begin{array}{lr}\text { Pengembangan data } & \text { server } \\
\text { pelanggan digunakan untuk } \\
\text { membackup data, sinkronisasi } \\
\text { data, kapasitas, } & \text { serta } \\
\end{array}$ & & & & & $\checkmark$ \\
\hline
\end{tabular}




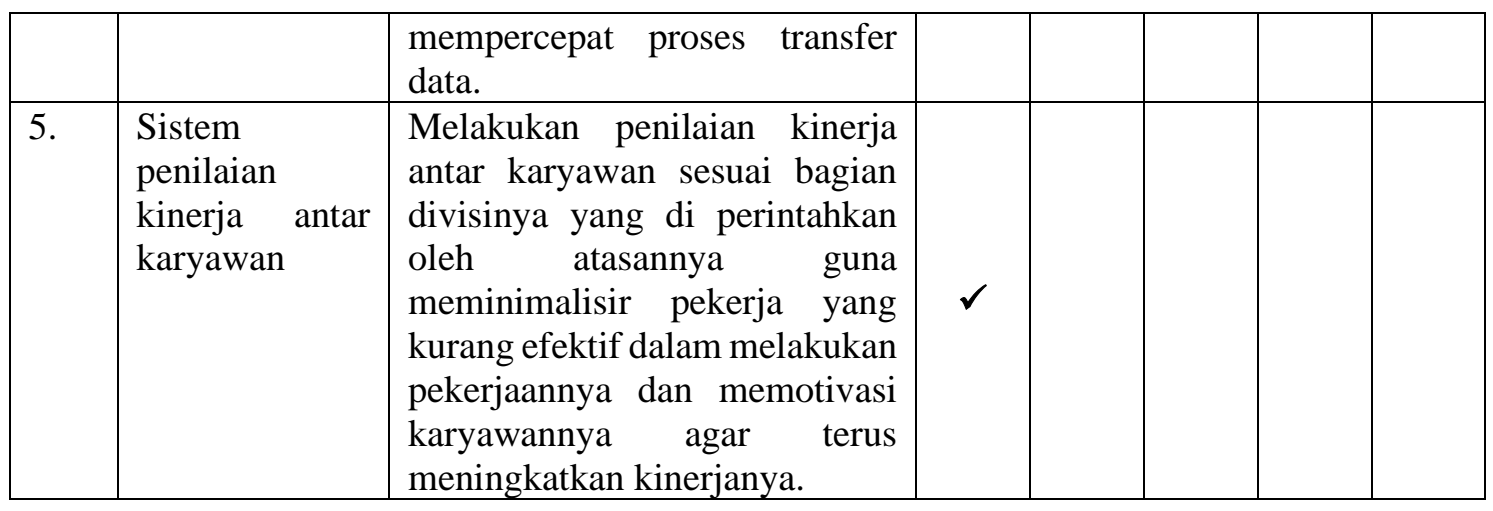

Tabel 3. Rekomendasi SI/TI

\section{KESIMPULAN}

Berdasarkan hasil analisa pada penelitian ini didapati kesimpulan bahwa SI/TI yang ada di PT. Telekomunikasi Indonesia, Tbk sudah baik adanya, hanya saja yang perlu diberi peningkatan yakni pada bagian kinerja karyawan dan peningkatan SDM. Peningkatan tersebut guna agar penerapan SI/TI yang ada pada PT. Telekomunikasi Indonesia, Tbk dapat digunakan dengan efektif dan efisien. Serta peningkatan kinerja yang baik kedepannya dapat memberikan nilai tambah bagi pelayanan perusahaan kepada konsumennya. Serta rekomendasi SI/TI yang diberikan juga dapat di implementasikan oleh perusahaan pada jangka 1-5 tahun mendatang.

Saran untuk penelitian selanjutnya diharapkan dapat melakukan analisa dan penerapan rekomendasi SI/TI saat ini dengan metode-metode yang lebih mendalam kembali. Dalam penelitian perencanaan startegis sistem informasi ini dapat ditarik kesimpulannya bahwa kinerja dan peningkatan SDM pada perusahaan yang perlu ditingkatakan agar kedepannya dapat memberikan nilai tambah bagi perusahaan. Diharapkan penelitian selanjutnya dapat meneliti lebih menyeluruh pada tiap aspek-aspek yang ada pada persuahaan saat ini.

\section{Referensi}

[1] M. Afriyano, E. Darwiyanto,ST., MT., and G. A. A. Wisudiawan, "Perencanaan Strategis Sistem Informasi Menggunakan Metode Ward and Peppard Pada PT. Grahacipta Bangko Jaya", eProceeding of Engineering, Vol.3, No.1 April 2016.

[2] Y. Septiana, "Perencanaan Strategis Sistem Informasi Dengan Pendekatan Ward And Peppard Model (Studi Kasus : Klinik INTI Garut) “, Wawasan Ilm., vol. 8, no. May pp. 8-24, 2017.

[3] W. I. Yudhistyra and E. Nugroho, "Lima Metode Perencanaan Strategis Sistem Informasi dan Teknologi Informasi untuk Pengembangan E-Government”, SENTIKA 2014.

[4] P. Y. Dewantara and Febriliyan Samopa, "Perencanaan Strategis Sistem Informasi / Teknologi Informasi Di Balai Riset Dan Standardisasi Industri Surabaya", TEKNOLOGI PROSES DAN INOVASI INDUSTRI, VOL. 2, NO. 2, NOVEMBER 2017

[5] S. Mawlan, S.Kom, M.T.I and Noviadi. 2014 "Perencanaan Strategis Sistem Informasi / Teknologi Informasi Pada Perusahaan Penjualan Mobil Dengan Pendekatan Jhon Ward And Joe Peppard Studi Kasus : PT Topcars Cabang Palembang"

[6] A.Wedhasmara,"LANGKAH-LANGKAH PERENCANAAN STRATEGIS SISTEM INFORMASI DENGAN MENGGUNAKAN METODE WARD AND PEPPARD “, J. Sist. Inf., vol 1, no.1, pp. 14-22, 2009. 